\title{
The expression patterns of HSP70 and HSP90 genes of abalone (Haliotis squamata) using 2- phenoxyethanol as an anaesthetic during transportation
}

\author{
Ngurah S. Yasa ${ }^{1, *}$, Lutfi Anshory ${ }^{1}$, Winarno $^{1}$, and Pande Gde Sasmita Julyantoro ${ }^{2}$ \\ ${ }^{1}$ National Broodstock Centre for Shrimp and Mollusk, Desa Bugbug, Karangasem Bali, 80811, \\ Indonesia \\ ${ }^{2}$ Department of Aquatic Resources Management, Faculty of Marine Science and Fisheries, Udayana \\ University, Bukit Jimbaran Campus, 80361 Bali, Indonesia
}

\begin{abstract}
The packaging of abalone (H. squamata) $(39.65 \pm 0.24 \mathrm{~mm} \mathrm{TL})$ for long-term transportation ( $>8$ hours) requires the addition of substances that provide an anesthetic effect so that it could reduce stress and maintain survival rate post transportation without having to repack. The objective was to investigate the expression pattern of HSP70 and HSP90 genes of abalone during transport with the addition of 2-phenoxyethanol. Abalone was packed using a styrofoam box with dimensions $\left(42.5 \times 75.5 \times 27.5 \mathrm{~cm}^{3}\right)$, containing 2 pcs of 10L Polyethylene (PE) plastic bags. The plastic bag consisted of 2 pcs of $25 \mathrm{~cm}$, 4-inch Polyvinyl Chloride (PVC) pipe for abalone attached. Both ends line enclosed with screen net and tied with rubber bands. Abalone density was 50 heads/pipe. Transportation tests were carried out using a dry system and wet system with and without the addition of 2-phenoxyethanol (PK, KK). Data analysis was done by paired sample ttest and ANOVA with a $95 \%$ confidence interval. The results showed that the best abalone survival $(85 \%)$ was obtained in wet transport +2 phenoxyethanol (PB) $(p<0.05)$ within 24 hours of transportation.
\end{abstract}

\section{Introduction}

The tropical abalone Haliotis squamata is one of the indigenous gastropods along the southern coast of Bali, Jawa, and Sumatera. This species is in great demand by consumers because it has similarities in shape and color to Taiwanese abalone tokobushi (H.diversicolor supertexta), which generally has a reddish round shell with a rough surface [1]. Due to its high demand, its capture in the wild tends to increase. As an impact, regardless of the cultivation, it is also becoming a target species for conservation.

In recent years, abalone stock enhancement programmed directed by the Indonesian Ministry of Marine Affairs and Fisheries was encouraged due to successful of hatchery

\footnotetext{
* Corresponding author: ngurahsyasa@gmail.com
} 
produced juveniles and the reduction of abalone stock in Bali waters and some islands in Indonesia. To maintain the survival rate of abalone for stock enhancement, a proper live transportation method is needed, which can reduce abalone stress so that it is not easy to die after transportation $[2,3,4,5]$. Stress on live transport can be caused by shocks, decreased oxygen levels, and high stock density causing organisms to respond by inducing a range of stress-responsible proteins, including chaperone molecules such as HSP70 and HSP90 [6].

Live fish transportation carried out using a closed system is classified into 2 parts, namely short term ( $<8$ hours) and long-term transportation ( $>8$ hours) [7]. The use of the closed system for abalone transport can be done with either dry or wet methods. The damp system transportation is carried out by adding $10-30 \%$ media water of the packaging volume. In contrast, the dry system gives minimal media water (remaining juice) on sponge sheets, PE net, styrofoam, and PVC plates. Transportation of abalone with a distance of $>12$ hours has been carried out on H. squamata for restocking purposes in Thousand Island, Jakarta, in 2016 (unpublished data). However, the survival rate was low during the transport even though repackaging had been carried out in Ancol, Jakarta.

Transport studies of several aquaculture species have been carried out in other countries such as abalone $H$. asinina [8] at different seed sizes with different temperatures, in Salmon (Onchorinchus mikiss) for breeding and restocking purposes [7], in carp (Cyprinus carpio) with the addition of 2-phenoxyethanol mixed with ethyl alcohol [9], as well as in European snapper fry (Dicentrarchus labrax L.) transported with the addition of 2-phenoxyethanol and propiscin [10]. However, the transport test of abalone (H. squamata) has never been carried out for more than 12 hours with the addition of 2-phenoxyethanol.

The study of HSP gene expression profile in response to different kinds of environmental stressors has been carried out on various species such as sea mussel, Chamelea gallina [11], Tilapia, Oreochromis mossambicus [12], Mytilus galloprovincialis [13], European oyster, Ostrea edulis [14], Japanese abalone, H. discus hannai [4], Tropical Abalone, H. squamata [15], Macrobrachium rosenbergii [16], and tiger prawns, Penaeus monodon [17]. However, observations of the expression pattern of the HSP70 and HSP90 as a response to abalone $(H$. squamata) transport shocks have not been carried out, where transport shocks are a factor causing stress.

Tropical Abalone, H. squamata, is a native species caught on the southern coast of Bali, which has delicious meat and high commercial value, this unique species has been cultivated mainly in Bali, Nusa Tenggara Barat (NTB), and Sulawesi in recent years. Due to its uniqueness and sensitivity to environmental stressors, these abalones could be used as animal models for studying molecular mechanisms of transport-induced cellular stress responses.

HSPs can be found in prokaryotic, archaea, and eukaryotic organisms [18]. These genes play an essential role in repairing denatured proteins and respond to various oxidative stresscausing factors such as heat shock, pathogenic infection, heavy metals, and xenobiotic $[19,20,21]$. HSP can be grouped into different families based on their molecular weight (kDa), such as small HSP, HSP60, HSP70, HSP90, HSP100, and HSP110 [6,20]. As we know, the HSP70 is the most conserved family, and the HSP90 is widely distributed in all body tissues and can be induced or expressed under heat shock stress [22].

Physiological stress response patterns during transport stress will help improve live transport techniques to enhance abalone immunity and protect them from the risk of death during long-term transport. Both HSP genes (HSP70 and HSP90) were observed for their expression patterns by observing abalone's haemolymph under 2-phenoxyethanol anesthetic and verifying the inducibility of both HSP genes under transport stress conditions. This report provides information on the time dependence of HSP70 and HSP90 expression patterns in haemolymph during and after transport conditions. In addition, SOD and PO activities were also tested on $H$. squamata haemolymph during the transport process to determine the possible role of antioxidant enzymes as part of the body's defense system in abalone. 
The purpose of this study was to investigate the expression patterns of both HSP genes under live transport conditions with the addition of 2-phenoxyethanol as an anesthetic and provide a better understanding of the stress response in an abalone.

\section{Materials and methods}

\subsection{Abalone preparation and transportation test}

Eight hundred hatchery-produced abalone juveniles with a shell length of $39.65 \pm 0.24 \mathrm{~mm}$ were reared in a $1 \mathrm{~m}^{3}$ black fiberglass tank before the study. The water exchange system was carried out by flow through, and the water temperature and salinity were maintained at $\left(27 \pm 2^{\circ} \mathrm{C}, \mathrm{RT}\right)$ and salinity was $30 \mathrm{ppt}$.

The transportation test was carried out with a dry system and a wet system. In the dry system, the abalone (in the transport module) was packed into a plastic bag without adding seawater, given oxygen gas, and tied with a rubber band so that oxygen did not come out. The styrofoam box with dimensions of $69.5 \times 36.5 \times 27 \mathrm{~cm}^{3}$ filled with 2 plastic bags $(67 \mathrm{x}$ $35 \times 27 \mathrm{~cm}^{3}$ ), and each bag filled with 2 PVC pipe modules (Figure 1). Meanwhile the transportation test of the wet system $(\mathrm{KB}=$ wet control and $\mathrm{PB})$ was carried out similar to the dry system $(\mathrm{KK}=$ dry control and $\mathrm{PK})$, but each bag filled with water at $10 \%$ of the volume. In a dry transportation treatment (PK), abalone was soaked first with $1 \mathrm{ppm}$ of 2phenoxyethanol for 5 minutes before being put and packaged in a plastic bag. Meanwhile, in the wet transportation treatment (PB) the transportation medium was given $1 \mathrm{ppm}$ solution of 2-phenoxyethanol without repackaging for 24 hours. Observation for falling rate, survival rate, and heamolymp withdrawal was conducted every 6 hours post transportation.

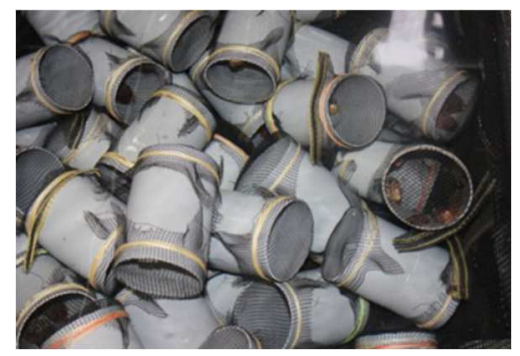

(A)

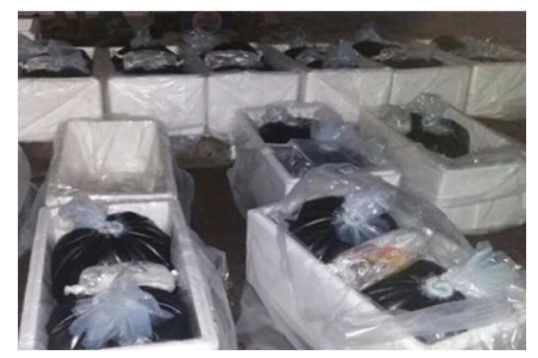

(B)

Fig. 1. Abalone in PVC pipe, cover with screen net and tied with rubber band (A) PVC pipe with abalone inside the PE plastic bags (B)

\subsection{Total RNA extraction was followed by cDNA synthesis}

Total RNA was isolated from abalone haemolymph using the Quick-RNA ${ }^{\circledR}$ MiniPrepPlus Kit (R1058) (Zymo Research, USA) according to the manufacturer's protocol. Total RNA was quantified by Spectrophotometer (NanoDrop ${ }^{\circledR} 2000$ Technologies, USA) at a wavelength A260 and the quality was checked at a ratio of A260/280 nm. ReverTra Ace ${ }^{\circledR}$ qPCR RT Master Mix (FSQ-301) (Toyobo, Japan) equipped with gDNA remover was used in cDNA synthesis according to the user guide. Each sample was eluted to have the same amount of RNA (50ng). The synthesized cDNA was stored at $-20^{\circ} \mathrm{C}$ before use. 
Tabel 1. Primers used in the real-time qRT-PCR

\begin{tabular}{|c|c|c|c|}
\hline Primers & Sequence (5'-3') & $\begin{array}{l}\text { Accession number } \\
\text { from gene bank }\end{array}$ & Reference \\
\hline $\begin{array}{l}\text { HSP70 F } \\
\text { HSP70 R }\end{array}$ & $\begin{array}{l}\text { CCGCTCTAGAACTAGTGGAT } \\
\text { CCGCCAAGTGGGTGTCT }\end{array}$ & AM283516 & [22] \\
\hline $\begin{array}{l}\text { HSP90 F } \\
\text { HSP90 R }\end{array}$ & $\begin{array}{l}\text { CCAGGAAGAATATGCCGAGT } \\
\text { CACGGAACTCCAACTGACC }\end{array}$ & AM283515 & [22] \\
\hline $\begin{array}{l}\beta \text {-actin F } \\
\beta \text {-actin R }\end{array}$ & $\begin{array}{l}\text { GGGTGTGATGGTCGGTAT } \\
\text { AGCGAGGGCAGTGATTTC }\end{array}$ & AM236595 & [22] \\
\hline
\end{tabular}

\subsection{Transcriptional analysis by real-time qRT-PCR}

The gene expression kit (SensiFAST SYBR ${ }^{\circledR}$ Lo-ROX Kit), cDNA, gene-specific primers (Table 1), and nuclease-free water were mixed into a volume of $20 \mu 1$ for transcriptional analysis of HSP70 and HSP90 genes into the real-time PCR machine (7000ABI, USA). To normalize mRNA, the gene encoding $\beta$-Actin was selected as the reference gene. The programmed thermal cycle conditions were $95{ }^{\circ} \mathrm{C}$ for 30 seconds, followed by 40 cycles of $95^{\circ} \mathrm{C}$ for 5 seconds, $58^{\circ} \mathrm{C}$ for 30 seconds, and $72^{\circ} \mathrm{C}$ for 30 seconds. Melting curve analysis was added $\left(65^{\circ} \mathrm{C}\right.$ to $95^{\circ} \mathrm{C}$, in increments of $\left.0.5^{\circ} \mathrm{C} / \mathrm{sec}\right)$. Gene expression analysis was determined based on a comparative method [27] normalized using $\beta$-actin as an internal control.

\subsection{SOD and PO activity}

The SOD and PO activity evaluation was initiated by withdrawing haemolymph from pallial sinus by 25 -gauge $1 \mathrm{ml}$ microsyringe during sampling before transportation $(0 \mathrm{~h})$ and 6,12 , $24 \mathrm{~h}$ after transportation test. The collected haemolymph was pooled from three animals and stored in $-20^{\circ} \mathrm{C}$ before being used. SOD activity was measured by SOD test kit (Dojindo, Japan) according to the instructions on the packaging. In principle, this test measured the photochemical reduction inhibition of nitroblue tetrazolium chloride (NBT) as previously described. [26]. Then the procedures for conducting the reactions were according to manufacture instructions. The optical density used for measuring SOD activity was at 450 $\mathrm{nm}$. Phenoloxidase activity was measured by mixing $100 \mu \mathrm{l}$ haemolymph plasma and $100 \mu \mathrm{l}$ L-DOPA, Sigma D9628 (30 mM L-3,4 dihydrophenylalanine in $0.2 \mathrm{M} \mathrm{HCl}, \mathrm{pH} 8$ ) into a 96well microplate. Then it was left for 10 seconds and measured with an ELISA reader (Heales ${ }^{\circledR}$ MB $\neg 580$, China) at an absorbance of $492 \mathrm{~nm}$. Conceptually it was done by recording the formation of dopachrome produced from L-3,4 dihydroxyphenylalanine (LDOPA) according to [28].

\subsection{Abalone's falling rate}

Changes in abalone adhesion to PVC substrates can be used to evaluate the health and vitality of abalone. The abalone attached to the PVC pipe was observed for each treatment for its adhesiveness. Furthermore, the number of fallen abalone was recorded every 6 hours. This experiment was carried out in three replications.

\subsection{Abalone's survival rate}


During 24 hours of transportation, the abalone mortality was recorded every 6 hours to count the survival rate. The death of the abalone is marked by the abalone falling from the place of attachment, with the inverted state or the shell position is at the bottom. Foot muscle movement and adhesion capability are lost, and a large amount of mucus is formed.

\section{Results}

To find out whether the transportation test can induce HSP70 and HSP90, we investigated the temporal expression of HSP70 and HSP90 in haemolymph after transport assays. In terms of transport stress, HSP70, and HSP90 in haemolymph increased significantly at 6 hours post-transport and peaked at 24 hours (10-20-fold) in HSP70 at all treatment, except for KB. On the other hand, the expression of HSP90 was significantly up-regulated at six h (4-5-fold) after the transportation test except for KB (Fig 2).

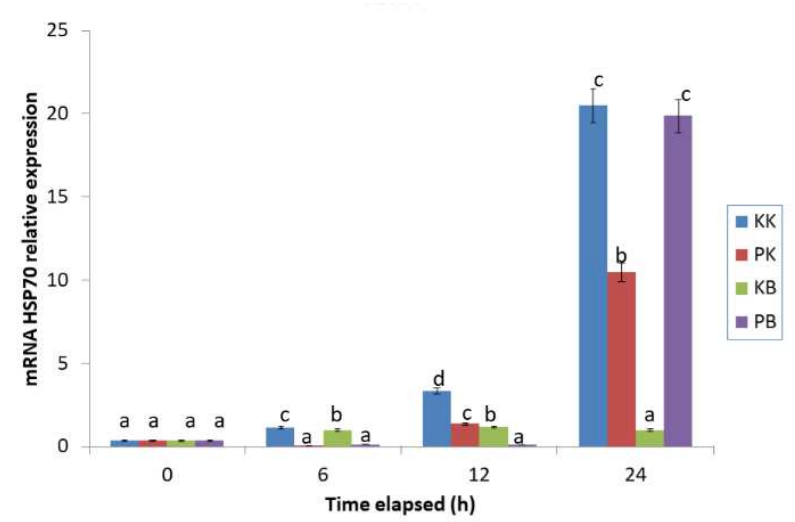

(A)

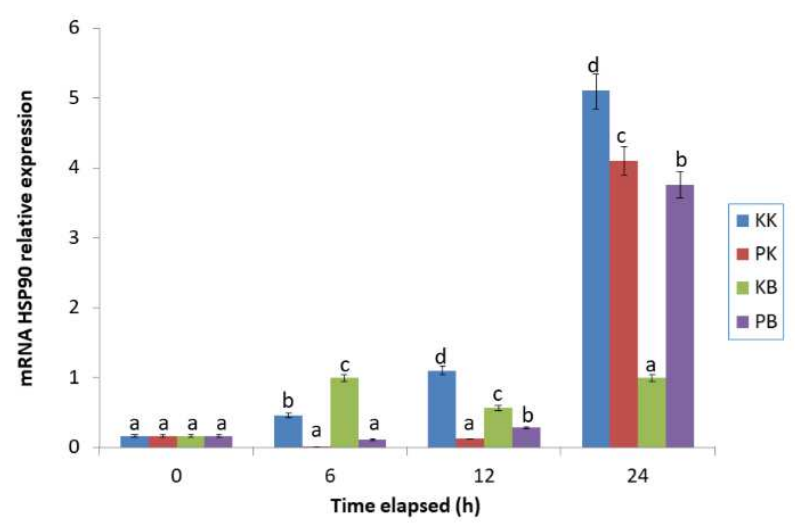

(B)

Fig. 2. Relative expression of mRNA HSP70 (A) and mRNA HSP90 (B) at different times under transportation test. Significant differences are indicated with different lowercase letters $(p<0.05)$. $\mathrm{KK}=$ dry control; $\mathrm{PK}=\mathrm{dry}$ anaesthetic treatment; $\mathrm{KB}=$ wet control; $\mathrm{PB}=$ wet anaesthetic treatment.

Haemolymph is a crucial component involved in the abalone body's defense system, such as phagocytosis to fight harmful microorganisms or foreign particles. Antioxidant enzymes contained in haemolymph play an essential role in oxidative stress, phagocytosis, and the 
scavenging of ROS. Therefore, the superoxide dismutase (SOD) activity and phenoloxidase (PO) activity were measured to determine the response of abalone to the transport test at 6 , 12,24 , and 24 hours post-transportation (hpt) compared to before the transport test $(0 \mathrm{~h})$. The graph showed that the activity of SOD was decreased after $6 \mathrm{~h}$ compared to the control until $24 \mathrm{hpt}$ (Figure 3a). Otherwise, the PO activity after transportation treatments was significantly increased almost (3-fold) after $6 \mathrm{hpt}$, and no quite different $(p>0.05)$ compared to the initial condition until 24 hours.

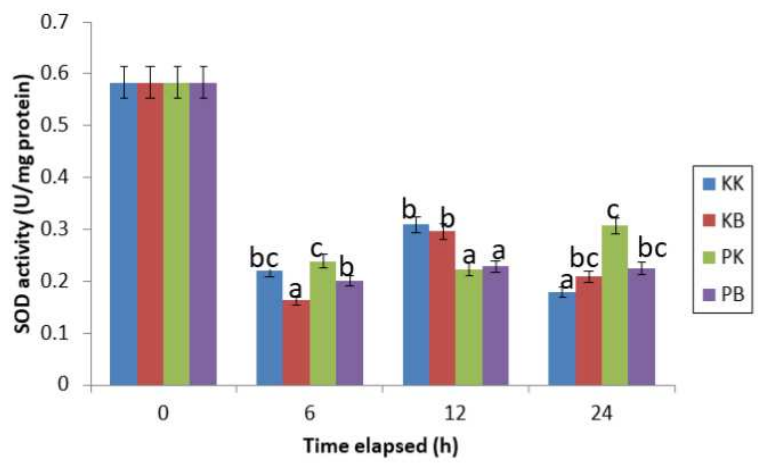

(A)

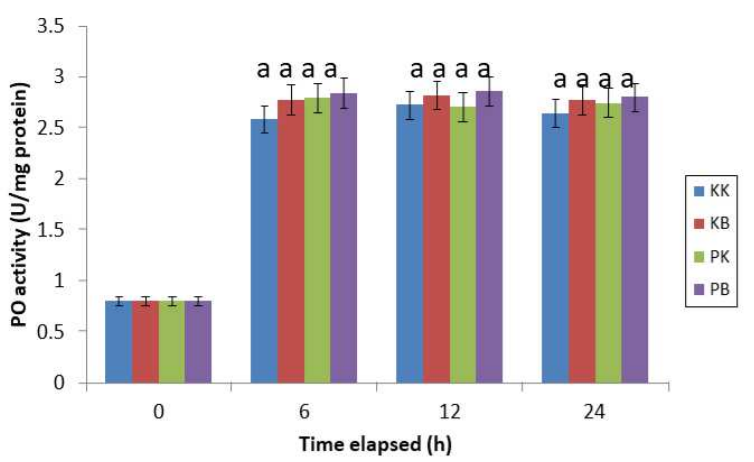

(B)

Fig. 3. SOD activity (A) and $\mathrm{PO}$ activity (B) of abalone (H. squamata) after transportation test. Significant differences are indicated with different lowercase letters $(p<0.05)$. $\mathrm{KK}=$ dry control; $\mathrm{PK}=$ dry anaesthetic treatment; $\mathrm{KB}=$ wet control; $\mathrm{PB}=$ wet anaesthetic treatment.

Abalone's ability to adhere to the substrates is an essential part of their health and vitality to adapt to different threats to environmental change. After undergoing the transport test, abalone resistance will be seen from its ability to adhere to the PVC substrate (falling rate), which in turn can affect abalone survival (Figure 4). 
(A)

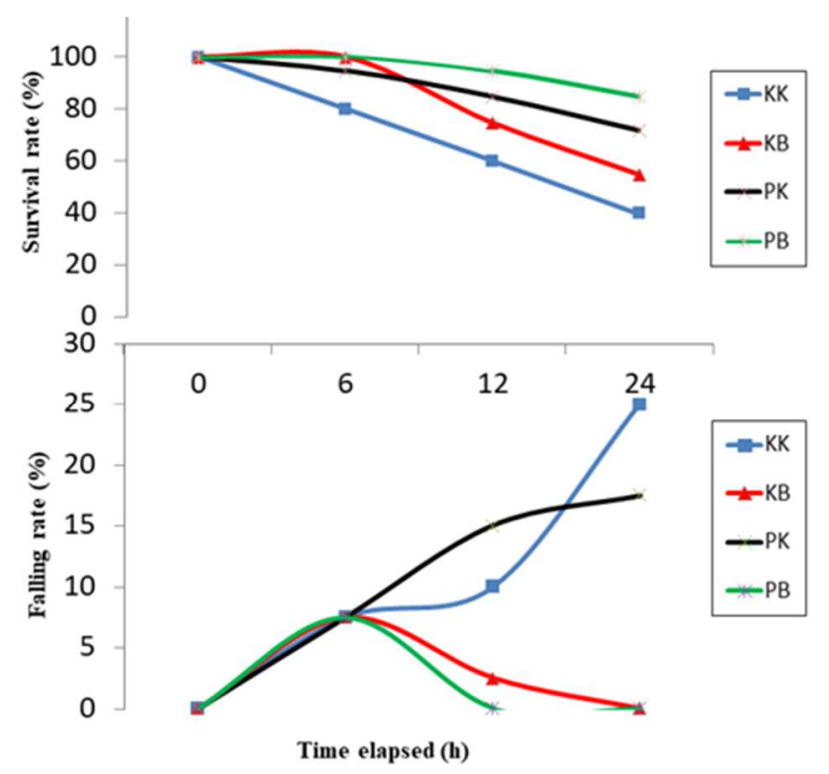

Fig. 4. Survival rate (\%) (A) and falling rate (\%) (B) of abalone (H. squamata) at different observation times after transportation test. $\mathrm{KK}=$ dry control; $\mathrm{PK}=$ dry anaesthetic treatment; $\mathrm{KB}=$ wet control; $\mathrm{PB}=$ wet anaesthetic treatment.

Based on the observation, there was a decreasing trend in survival rate for all treatment during transportation. Nevertheless, the 2-phenoxyethanol treatment (PK and PB) showed a higher survival rate than the control group (KK and $\mathrm{KB})$. However, abalones at dry basis after $6 \mathrm{hpt}$ showed falling rates as $10 \%, 20 \%$, and $30 \%$ respectively. Otherwise, the wet basis treatment showed a reduced in falling rate after $6 \mathrm{~h}$ post transportation.

\section{Discussions}

General anesthetic 2-phenoxy ethanol or ethylene glycol monophenyl ether (EGPE) has become a standard in aquaculture activities to transport freshwater fish and seawater fish species. In general, the tranquilizing effect of $1 \mathrm{ppm}$ 2-phenoxy ethanol occurred until 12 hours post transportation. Furthermore, the expression level of all treatments increased significantly at 24 hours. While HSP reaches peak abundance, heat shock transcription factor (HSF) will bind to HSP and lose DNA binding activity on heat shock elements (HSE), this results in decreased expression levels of the HSP gene for binding to HSF1, with the result that the released HSF1 can now undergo trimerization and translocation to the nucleus to activate HSP transcription $[18,25]$. Previous studies also indicated that there was an elevate in the expression level of HSP70 and HSP90 under transport triggers a stress response in Channel catfish (Ictalurus punctatus) liver and in several tissues of common carp (Cyprinus carpio) and rainbow trout (Oncorhynchus mykiss) exposed to transport stress [29, 30]. The increment in HSPs may reflect the improved ability of those fishes to adapt to transport stress.

Heat shock protein (HSP) is a general term for chaperonin molecules, the genes responsible for stress response $[6,12]$. Both genes were studied, measuring 70kDa (HSP70) and $90 \mathrm{kDa}$ (HSP90), and these genes are found in the cytoplasm, mitochondria, and nucleus [31] and will experience increased expression due to changes in environmental quality that cause exposed organisms to experience stress [22, 17, 12]. In general, the expression level of 
the HSP70 gene increased at 24 hours, except for the wet control treatment (KB), which remained low until the end of the transportation test. The higher expression was seen at $6 \mathrm{~h}$ and $12 \mathrm{~h}$, then decreased at 24 hours. In the dry basis control, expression increased over time, and the peak occurred at 24 hours. In the dry treatment (PK) an increase in expression was seen starting at 12 hours, while at 6 hours it seemed low, it was suspected that the anesthetic effect of 2-phenoxyethanol on abalone was strong enough to tranquilize the juvenile at that time. While in the wet treatment (PB) the expression of the HSP70 gene was not significantly different until the $12 \mathrm{~h}$, but increased dramatically at $24 \mathrm{~h}$, this is presumably the effect of 2phenoxyethanol anesthesia has reduced so that the abalone condition recovers and begins to stress as seen from the results of the high HSP70 gene expression $(p<0.05)$.

Likewise, the HSP90 expression at both control (KK and KB) generally increase significantly over time $(p<0.05)$, from 6 to 24 hours post transportation (Figure 2$)$. In the dry control treatment $(\mathrm{KK})$ the expression seemed to increase, while the dry treatment $(\mathrm{PK})$ and wet treatment (PB) began to increase significantly at 24 hours. While in the damp control treatment $(\mathrm{KB})$, gene expression seemed relatively stable, only slightly increased at $6 \mathrm{~h}$ and 12 hours.

The cellular defense response of SOD during abalone transport is shown in Figure 3A. In general, SOD activity appears to decrease when compared to the initial condition $(0 \mathrm{~h})$. The SOD activity was significantly increased $(p<0.05)$ at $6 \mathrm{~h}$ and $24 \mathrm{~h}$ for both treatments (PK and $\mathrm{PB}$ ) if we compare to the control. Otherwise, at $12 \mathrm{~h}$, SOD activities were significantly lower than control. The SOD activity indicated the ability of abalone to neutralize free radicals like superoxide $\left(\mathrm{O}_{2}{ }^{-}\right)$anion that cause cell damage [32, 33]. Decreased SOD levels are related to the accumulation of free radicals, which disrupt cell function [34].

The phenoloxidase activity during the transportation process generally increases after 6 $\mathrm{h}$ and lasts up to 24 hours. However, the significant difference was only in the 6-hour PB treatment $(p<0.05)$ post-transport compared to other treatments. Subsequent PO activity appeared to be similar in all treatments up to 24 hours. The PO response in all treatments appeared to be higher than the initial condition. In the anesthetized condition, the PO response to abalone was also increased until the end of the experiment. The application of clove oil (CO) as an anesthetic as much as $25 \mathrm{mg} / \mathrm{L}$ to Rainbow Trout can increase lysozyme and bactericidal activity, but in this study, 2-phenoxy ethanol did not cause a bactericidal effect so that bacterial growth increased during transportation. This could be detected by the PO system. The production of PO is dependent upon a pro PO-activating system, which begins with the presence of lipopolysaccharide, peptidoglycan, laminarin, and $\beta$-1, 3-glucans $[35,36]$. The sensitivity of PO activity to transportation stress suggests that this enzyme might be another reliable marker of this study.

Survival of abalone juveniles during transportation generally decreased after 6 hours to 24 hours post transportation. The most drastic decrease in survival was seen in the treatment of KK followed by KB, PK, and the highest survival rate was PB. Both dry and wet anesthetic treatments (PK and $\mathrm{PB}$ ) showed higher survival rates than the controls (KB and $\mathrm{PB}$ ) (Figure $4 \mathrm{~A})$. In contrast to the falling rate at dry treatment, both control (KK) and PK experienced a decrease in adhesion ability compared to wet control (KB) and wet treatment (PB) (Figure 4B). The adhesion ability of abalone without water media decreased from $6 \mathrm{~h}$ to 24 hours.

On the other hand, the decrease in the adhesion ability of transportation with water media, which initially increased in the first 6 hours, decreased after 6 hours after transport. This shows that the application of water media can maintain the abalone attached to the PVC substrate. The decrease in adhesion ability was suspected to be still under stress and try to adapt to the initial conditions. After $6 \mathrm{~h}$, abalone was able to adapt, and its adhesion ability to the substrate increased, as evidenced by a decrease in the falling rate. 


\section{Conclusion and suggestion}

The stress level of abalone based on HSP70 and HSP90 genes expression had a similar pattern, where during the transport test (0-12 hours), it was pretty low in all treatments and seemed to increase at 24 hours. The SOD activity was generally decreased during the live transport. The PO activity was raised during the live transport process. Falling rate increased in dry treatment $(\mathrm{PK})$ and dry control $(\mathrm{KK})$ and decreased in wet control $(\mathrm{KB})$ and wet treatment $(\mathrm{PB})$. The highest survival rate was obtained in treatment (PB) $85 \%$ followed by (PK) $72 \%$, (KB) $65 \%$, and the lowest was in therapy (KK) $40 \%$.

The results of this study indicate that both chaperones (HSP70 and HSP90) can be involved in the adaptability of abalone to stress conditions caused by transportation. Furthermore, the activity of SOD and PO enzymes showed different immune responses during abalone transport stress. These findings will help to understand the importance of the two HSP genes, the enzymes SOD and PO, to provide defenses for abalone against stress. Further investigation is needed to elucidate the mechanism of action of the two HSP genes, SOD and PO enzymes, participating in the abalone immune reaction.

\section{Acknowledgments}

We acknowledge for supported funding by BPIU2K, DJPB-KKP through DIPA T.A. 2020 with the number of 445394/BPIU2K.K/DIPA/2020. We appreciate to Mrs. Putu Sumaryati and Mr. B.R. Basuki for their help in Lab Kesling BPIU2K.

\section{References}

1. NCBI. National Centre for Biotechnology Information. $<$ https://www.ncbi.nlm.nih.gov/taxonomy/Browser/wwwtax.cgi?id=2017615 (2020)

2. Beltran, C.A., R. S. Bernall, M. L. L. Partida. Dis. Aquat. Org. Vol. 33:119-122. (1998)

3. Wu, J.P., Chen, H.C., Huang, D.J. Chemosphere. 73: 1019-1026. (2008)

4. Park, K., Lee, J.S., Kang, J.-C., Kim, J.W., Kwak, I.S. Fish \& Shell. Immunol. 42: 233-240. (2015)

5. Yasa, N.S., Murwantoko, Isnansetyo A, Handayani N.S.N., Triastutik G, Anshory L. IJB. 25 (1): 12-20. (2020)

6. Parsell, D.A., Lindquist, S. Annu. Rev. Genet. 27: 437-496 (1993)

7. Sampaio, F.D.F., Freire, C. A., Fish and Fisheries, 17, 4 (2016)

8. Ursua, S.M.A.B, G.Ludevese. Aquac. Res., 42:1206-1213 (2011)

9. Altun, T., D. Danabas. The Israeli J. of Aquac.-Bamigeh, 58 (3), 178-182 (2006)

10. Lucic, J.M., I. Mladineo and M. Tudor. Aquac. Internat., 13,(2005)

11. Monari, M., J.Foschi, R. Rosmini, M.G.Marin, G.P. Serrazanetti. J. of Exp. Marine Biol. and Ecol. 397 (2011)

12. Molina, A., Biemar, F., Müller, F., Iyengar, A., Prunet, P., Maclean, N., Martial, J.A., Muller,M. FEBS Lett. 474 (2000)

13. Cellura, C., M. Toubiana, N. Parrinello, \& P. Rocha. Develop and Compar. Immunol., 30 (2006) 
14. Piano, A., S. Franzellitti, F. Tinti, E. Fabbri. Gene, 361 (2005)

15. Yasa, N.S., Murwantoko, Isnansetyo A, Handayani N.S.N., Triastutik G, Anshory L. Bioflux, 12 (2019)

16. Liu J, Yang W-J, Zhu X-J, Karouna-Renier NK, Rao RK. Cell Stress Chaperones. 9 (2004)

17. Lo W-Y, Liu K-F, Liao I-C, Song Y-L. Cell Stress Chaperones. 9 (2004)

18. Morimoto, R.I., Tissieres, A., Cesrgopoulos, C. Science, 259 (1993)

19. Sharma, S.K., Christen, P., Goloubinoff, P. Curr Protein Pept. Sci. 10, 5 (2009)

20. Feder M. E., Hofmann G. E. Annu. Rev. of Physiol., 61 (1999)

21. Moseley, Immunopharmacology., 48, (2000)

22. Farcy, E., Serpentini, A., Fiévet, B., Lebel, J.M. Comp. Biochem. Physiol.- B Biochem. Mol. Biol. 146 (2007)

23. De la Vega, E., B. M. Degnan, M. R. Hall, J.A. Cowley, K. J. Wilson. Dis. Aquat. Org., 59 (2004)

24. Jiang S, Qiu L, Zhou F, Huang J, Guo Y, Yang. K. Mol. Biol. Rep.: 36, 1 (2009)

25. Tachibana, T., S. Astumi, R. Shioda, M. Ueno, M. Uritani, T. Ushimaru. J. Biol. Chem., 277 (2002)

26. Datkhile, K.D., Mukhopadhyaya, R., Dongre,T.K., B.B. Nath. Comp. Biochem. and Physiol. Part C, 149 (2009)

27. Livak, K.J. \& Schmittgen, T.D. Methods. 25 (2001)

28. Hooper,C., R. Day, R. Slocombe, K. Benkendorff, J. Handlinger, J. Goulias, Aquaculture, 432 (2014)

29. Refaey, M.M., D. Li. Frontiers in Physiol, (2018)

30. Poltronieri, C., E. Negrato, D. Bertotto, D. Majolini, C. Simontacchi, G. Radaelli. Europ. J. of Histochem 52, 3 (2008)

31. Lawrence, A., K. Hemingway, Effects of pollusion on fish (Blackwell Science, Oxford, 2004)

32. Zhou, J., W.Na Wang, W.Y. He, Y. Zheng, L. Wang, Y. Xin, Y. Liu, A. Li Wang. J of Inver. Pathol. 103, (2010)

33. Parrilla-Taylor, D.P., T.Z. Savin, F.J.M. Barajas, Aquaculture, 380-383 (2013)

34. O.K. Okamoto, P. Colepicolo, Comp. Biochem. Phys. C 119, 1 (1998)

35. Asokan, R., Arumugan, M., Mullainadhan, P. Develop, Comp. Immunol, 21 (1997)

36. Cerenius, L., Söderhall, K. Immunol. Reviews 198 (2004) 